\title{
A Quick update from the Past to Current Status of Human Pluripotent Stem Cell-derived Hepatocyte cullture systems
}

\author{
Ensieh Zahmatkesh, Massoud Vosough*
}

- Department of Stem Cells and Developmental Biology, Cell Science Research Center, Royan Institute for Stem Cell Biology and Technology, ACECR, Tehran, Iran

\begin{tabular}{|c|c|}
\hline KEYWORDS & ABSTRACT \\
\hline Pluripotent stem cell & $\begin{array}{l}\text { Pluripotent stem cells (PSCs) may be offered as an unlimited cell source for the } \\
\text { hepatocyte generation. The generation of hepatocytes from stem cells in vitro would }\end{array}$ \\
\hline Hepatocyte differentiation & provide an alternative cell source for applications in drug discovery and cell \\
\hline Tissue engineering & transplantation. In this review, we discuss different approaches to generate \\
\hline Organoids & pluripotent stem cell-derived hepatocytes, advantages, limitations for each method \\
\hline Drug-screening & -derived hepatocytes. \\
\hline
\end{tabular}

Article Info

Received 2019/02/12;

Accepted 2019/03/19;

Published Online 2019

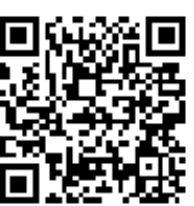

Corresponding Information: Massoud Vosough MD, Ph.D., Royan Institute, Banihashem Sq., Banihashem St., Resalat Highway, P.O. Box 16635-148, Tehran, Iran. Postal Code: 1665659911, Tel: +98 21 22306485, Fax: +98 21 23562507, Email: masvos@ royaninstitute.org

Copyright $($ C) 2019. This is an open-access article distributed under the terms of the Creative Commons Attribution-noncommercial 4.0 International License which permit copy and redistribute the material just in noncommercial usages, provided the original work is properly cited.

\section{Introduction}

The liver exposes to different diseases, including inherited metabolic disorders and other disorders caused by variety of factors. Currently, orthotopic liver transplantation (OLT) is the only effective treatment for life-threatening liver problems. However, transplantation of allogeneic hepatocytes has now become an alternative approach, which is less invasive than OLT (1). Hepatocyte transplantation has been limited due to the shortage of organ donors, efficient isolation, and cryopreservation challenges. The liver is also a key organ to assess the pharmacokinetics and pharmacodynamics of drugs and toxicology studies of xenobiotics (2). All these issues have highlighted the need to explore other sources of cells, e.g., stem cells that can be expanded sufficiently and then differentiate them into functional hepatocytes. Human PSCs have opened novel pathways in the field of regenerative medicine in terms of cell therapy and tissue engineering. Moreover, hPSCs have created a unique model system for studying diverse fields, from basic scientific questions such as developmental processes to the practical application including drug screening (3). 
Until now, various protocols have designed for hepatocyte differentiation and have tried to mimic the liver organogenesis during development by adding different substrates and growth factors, which are necessary for each developmental stage. However, the obtained hepatocytes showed an immature phenotype $(4,5)$. There are several ideas that can overcome the drawbacks in this regard to producing more mature hepatocytes (6).

\section{Hepatocyte differentiation in two- dimensional culture}

Currently, researchers have succeeded to develop the number of protocols for generating hepatocyte from hPSCs in 2D culture system. However, the hepatocyte-like cells (HLCs) generated in this protocols has indicated an immature phenotype with low hepatocyte functionality compared to primary human hepatocyte $(7,8)$. Monolayers of adherent $2 \mathrm{D}$ cells can grow on a coated flat and rigid surface such as polystyrene or glass (9). The $2 \mathrm{D}$ cell culture plays an essential role in the better understanding of the developmental biology and tissue morphogenesis. The monolayer cultures have faced many disadvantages regarding emulating in vivo conditions and providing physiological relevance. In addition, $2 \mathrm{D}$ cultures are unable to mimic the natural structures of tissues and the interactions will be missed in this type of culture that is responsible for cell differentiation, proliferation, viability, expression of genes and proteins, inducing stimuli, drug metabolism, and other cellular functions. Altogether, 3D approach has been used to improve maturation of HLCs and more emulation in vivo condition (10)

\section{Hepatocyte differentiation in three- dimensional culture}

Embryoid bodies (EBs) are 3D aggregates of hPSCs that can differentiate into three germ layers (endoderm, ectoderm, and mesoderm). EBs use as a model that can easily represent what is happening during in vivo development (11). A study has reported by Baharvand et al. that showed used EBs of hPSCs for hepatocyte differentiation (12). Using a dynamic 3D culture in a bioreactor for hepatocyte differentiation is the other method that can improve the hepatic maturation of hiPSC-derived (13). Vosough and his research team have succeeded to produce a scalable platform for hepatocyte differentiation from hPSCs using the mentioned system (14). Liver organoids provide a new class of biological model to serve as both tissue and organ. This approach could recapitulate many key parameters of in vivo conditions for instance, cellcell and cell-ECM interactions and the complexities of the tissue (15). Recently Takebe et al. have indicated that mimicking the embryonic niche by culturing hepatic endoderm cells with stromal cells (endothelial and mesenchymal lineages), can be a new approach to hepatocyte differentiation and liver organoid generation from hPSCs (16).

\section{Conclusion}

In conclusion, numerous 3D cell culture systems have improved over the past two decades. The existing evidence strongly has proved the 3D cell cultures that develop cell-cell and cell-ECM interactions, can imitate the specificity of native tissue with further physiological relevance more than conventional $2 \mathrm{D}$ cultures.

\section{References}

1. Giuseppe Pettinato, Rajesh Ramanathan, Robert A Fisher, Martin J. Mangino, Ning Zhang \& Xuejun Wen. Scalable Differentiation of Human iPSCs in a Multicellular Spheroid based 3D Culture into Hepatocyte-like Cells through Direct Wnt/ $\beta$ - catenin Pathway Inhibition. Sci Rep. 2016. Sep 12; 6:32888.

2. Richard Siller, Sebastian Greenhough, Elena Naumovska, and Gareth J. Sullivan. Small-Molecule Driven Hepatocyte Differentiation of Human Pluripotent Stem Cells. Stem Cell Reports.2015. 12;4(5):939-52.

3. Kevin G. Chen, Barbara S. Mallon, Ronald D.G. McKay, and Pamela G. Robey. Human Pluripotent Stem Cell Culture: Considerations for Maintenance, Expansion, and Therapeutics. Cell Stem Cell. 2014 Jan 2;14(1):13-26. 
4. Sullivan GJ, Hay DC, Park IH, et al. Generation of functional human hepatic endoderm from human induced pluripotent stem cells. Hepatology. 2010; 51:329-335.

5. Hannan NR, Segeritz CP, Touboul T, et al. Production of hepatocyte-like cells from human pluripotent stem cells. Nat Protoc. 2013; 8:430-437.

6. Nora Freyer, Fanny Kno“" spel, Nadja Strahl, Leila Amini, Petra Schrade, Sebastian Bachmann, Georg Damm, Daniel Seehofer, Frank Jacobs, Mario Monshouwer, and Katrin Zeilinger. Hepatic Differentiation of Human Induced Pluripotent Stem Cells in a Perfused ThreeDimensional Multicompetent Bioreactor. Biores Open Access. 2016 Aug 1;5(1):23548.

7. Baharvand $\mathrm{H}$, Hashemi SM, Shahsavani M. Differentiation of human embryonic stem cells into functional hepatocyte-like cells in a serum-free adherent culture condition. Differentiation 2008; 76:465-477.

8. Agarwal S, Holton KL, Lanza R. Efficient differentiation of functional hepatocytes from human embryonic stem cells. Stem Cells 2008; 26: 1117-1127.

9. Breslin S, O'Driscoll L. Threedimensional cell culture: the missing link in drug discovery. Drug Discov Today 2013; 18: 240-9.

10. Marta Kapałczyńska, Tomasz Kolenda, Weronika Przybyła, Maria Zajączkowska, Anna Teresiak, Violetta Filas, Matthew Ibbs, Renata Bliźniak, Łukasz Łuczewski, Katarzyna Lamperska.
2D and 3D cell cultures - a comparison of different types of cancer cell cultures. Archives of Medical Science. 2016. 17341922.

11. Gerecht-Nir, S., Cohen, S. \& Itskovitz-Eldor, J. Bioreactor cultivation enhances the efficiency of human embryoid body (hEB) formation and differentiation. Biotechnol Bioeng.2004. 86, 493-502.

12. Baharvand H, Hashemi SM, Kazemi Ashtiani S, Farrokhi A. Differentiation of human embryonic stem cells into hepatocytes in 2D and 3D culture systems in vitro. Int J Dev Biol. 2006;50(7):645-52.

13. B. Lucendo-Villarin, H. Rashidi, K. Cameron and D. C. Hay. Pluripotent stem cell derived hepatocytes: using materials to define cellular differentiation and tissue engineering. J Mater Chem B Mater Biol Med. 2016 May 28;4(20):3433-3442.

14. M. Vosough, E. Omidinia, M. Kadivar, M.-A. Shokrgozar, B. Pournasr, N. Aghdami and H. Baharvand, Stem Cells Dev., 2013, 22, 2693-2705.

15. Xiaolei Yin, Benjamin E. Mead, Helia Safaee, 1,2,3,4 Robert Langer, Jeffrey M. Karp and Oren Levy. Engineering Stem Cell Organoids. Cell Stem Cell. 2016:12:005.

16. Takebe, T., Sekine, K., Enomura, M., Koike, H., Kimura, M., Ogaeri, T., Zhang, R.R., Ueno, Y., Zheng, Y.W., Koike, N., et al. Vascularized and functional human liver from an iPSCderived organ bud transplant. Nature. 2013; $499,481-484$.

\section{How to cite this article:}

Zahmatkesh E, Vosough M. A Quick update from the Past to Current Status of Human Pluripotent Stem Cell-derived Hepatocyte culture systems. Mod Med Lab J. 2019; 2(1) :110-112 